Check for updates

Cite this: Chem. Commun., 2020, 56, 10786

Received 29th June 2020,

Accepted 29th July 2020

DOI: $10.1039 / \mathrm{d} 0 \mathrm{cc} 04477 f$

rsc.li/chemcomm

\section{The terpyridine isomer game: from chelate to coordination network building block $\dagger$}

\begin{abstract}
Catherine E. Housecroft (D)* and Edwin C. Constable (D)
The first $4,2^{\prime}: 6^{\prime}, 4^{\prime \prime}$-terpyridine $\left(4,2^{\prime}: 6^{\prime}, 4^{\prime \prime}\right.$-tpy) containing coordination polymer was reported over

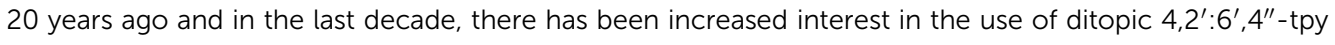
ligands as linkers in coordination polymers and 2D-networks. Functionalization in the $4^{\prime}$-position of $4,2^{\prime}: 6^{\prime}, 4^{\prime \prime}$-tpy is synthetically straightforward, giving access to a large suite of building blocks. Less well explored is the coordination chemistry of $3,2^{\prime}: 6^{\prime}, 3^{\prime \prime}$-tpy ligands which exhibit greater conformational flexibility than $4,2^{\prime}: 6^{\prime}, 4^{\prime \prime}$-tpy. One approach to making the transition from 2D- to 3D-networks is to

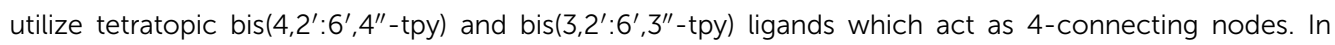
this highlight, we survey recent progress towards a better understanding of the design principles

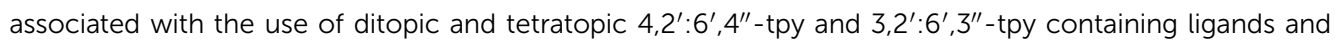
their roles both as linkers and nodes in coordination assemblies.
\end{abstract}

\section{Introduction}

Ask a class of chemistry undergraduates to draw the structure of 'terpyridine' and they will most likely think of only one isomer: $2,2^{\prime}: 6^{\prime}, 2^{\prime \prime}$-terpyridine (tpy, Fig. 1a). Its coordination

Department of Chemistry, University of Basel, BPR 1096, Mattenstrasse 24A, 4058 Basel, Switzerland. E-mail: Catherine.Housecroft@unibas.ch

$\dagger$ This article is dedicated to our friend and colleague Alan Welch on the occasion of his retirement from Herriot-Watt University. chemistry is that of a typical bis-chelating ligand, ${ }^{1,2}$ although hypodentate modes of bonding, in which fewer than the maximum possible number of chelating donors are bound to a metal centre, are also possible. ${ }^{3,4}$ This article concerns the use of terpyridine ligands for the assembly of coordination poly-

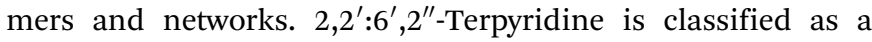
convergent tridentate ligand, and its coordination chemistry with d-block metal ions is typified by the formation of octahedral $\left\{\mathbf{M}(\text { tpy })_{2}\right\}^{n+}$ complexes (Fig. 1b). Thus, an entry into the

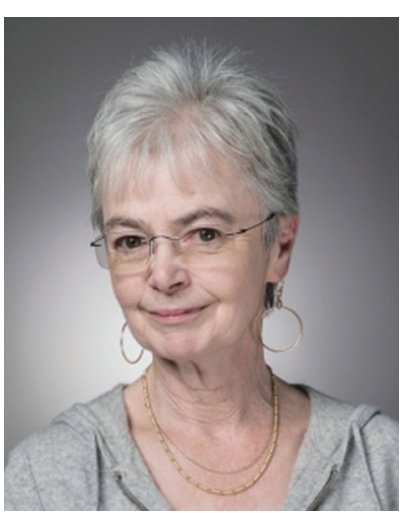

Catherine E. Housecroft
Catherine Housecroft is Titular Professor of Chemistry at the University of Basel. She is codirector of a highly active research group with her husband Edwin Constable. The research group has broad interests in coordination, structural, materials and interfacial chemistries with targeted applications in sustainable energy. In addition to contributing over 500 papers to the chemical and materials science research literature,

Catherine is an internationally recognized author of undergraduate textbooks: Chemistry (with Edwin Constable) and Inorganic Chemistry (originally with the late Alan Sharpe) are in their 4th and 5th editions, respectively, and Inorganic Chemistry has been translated into 7 languages.

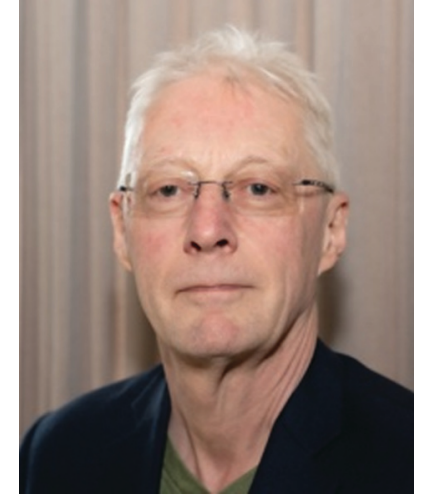

Edwin C. Constable
Edwin Constable is Professor of Chemistry at the University of Basel. He is an enthusiastic communicator of science and publishes widely in all areas of chemistry with some 700 peerreviewed publications, books and book chapters and is highly cited (22573 citations, h-index 74). His interests cover all aspects of chemistry, chemical history and the communication of science. He held an ERC Advanced Grant with his project "Li-Lo: Light-in, light-out", in which he developed concepts of a sustainable materials chemistry with particular reference to applications in solar cell and new lighting technologies. He is a titular member of Division VIII of IUPAC and is president of Euresearch. 


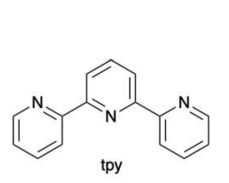

(a)

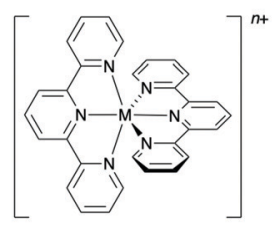

(b)

(c)

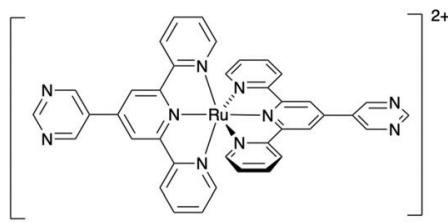

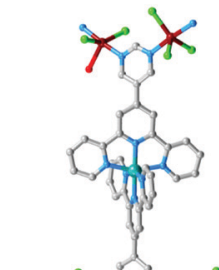

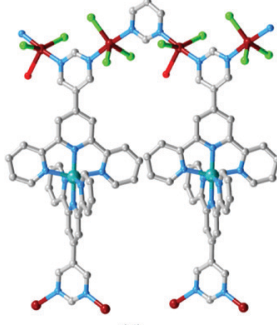

(d)
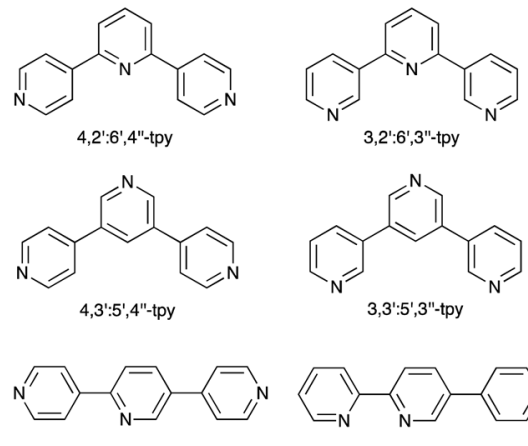

4,2':5',4"-tpy

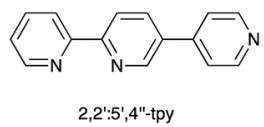

Scheme 1 Structures of some of the 48 isomers of terpyridine. The abbreviation tpy with no prefix is reserved for $2,2^{\prime}: 6^{\prime}, 2^{\prime \prime}$-terpyridine (Fig. 1a).

Fig. 1 (a) The structure of $2,2^{\prime}: 6^{\prime}, 2^{\prime \prime}$-terpyridine (tpy) showing the trans,trans conformation of the free ligand. (b) The $\left\{M(t p y)_{2}\right\}$-motif with the ligand in the cis,cis conformation adopted in the bis-chelate. (c) An example of an $\left\{M(t p y)_{2}\right\}$-centred expanded ligand, and (d) its use as a building block in a 2D-coordination network (CSD refcode BODGOR, with $\mathrm{H}$ atoms omitted).

realm of coordination polymers and networks requires functionalization of the tpy ligand by a second metal-binding domain such as a heterocycle or carboxylate to produce an $\left\{\mathrm{M}(\mathrm{tpy})_{2}\right\}-$ centred 'expanded ligand'. ${ }^{5}$ An example is shown in Fig. 1c, and reaction of this complex with $\mathrm{CuCl}_{2} \cdot 2 \mathrm{H}_{2} \mathrm{O}$ yields a 2D-network $\left\{\left[\mathrm{Ru}\left(4^{\prime} \text {-pymtpy }\right)_{2}\right]\left[\mathrm{CuCl}_{2}\left(\mathrm{OH}_{2}\right)\right]\left[\mathrm{CuCl}_{3}\right] \mathrm{Cl}_{\}_{n}}\left(4^{\prime}\right.\right.$-pymtpy $=4^{\prime}-(5-$ pyrimidinyl)-2,2' $: 6^{\prime}, 2^{\prime \prime}$-terpyridine), part of which is shown in Fig. 1 d. ${ }^{6}$ Fortunately, functionalization in the $4^{\prime}$-position of tpy is readily accomplished using either Wang and Hanan's onepot strategy ${ }^{7}$ or the Kröhnke methodology. ${ }^{8}$ On occasion, cyclic products (easily recognized from their ${ }^{1} \mathrm{H}$ NMR spectroscopic signatures compared to that of a tpy) result for particular $4^{\prime}$ substituents; the reasons for this remain unclear. ${ }^{9}$

Even though expanded ligands of the type shown in Fig. 1c are readily accessible, they retain an $\{\mathbf{M}(\mathrm{tpy})\}_{2}$ core which may limit exploitation in network assemblies to low connectivities at this metal centre. Oligopyridines with divergent sets of donor atoms are more suitable for use as building blocks in coordination polymers and networks, and the 48 possible isomers of terpyridine provide a playground for the coordination chemist. In practice, however, only $4,2^{\prime}: 6^{\prime}, 4^{\prime \prime}$-tpy and $3,2^{\prime}: 6^{\prime}, 3^{\prime \prime}$-tpy (Scheme 1) have been used to any great extent. Searches in the Cambridge Structural Database (CSD v. 5.4.1) ${ }^{10}$ for extended coordination assemblies involving other isomers of terpyridine reveal few hits. We ignore instances where the isomer is a motif within a larger structure such as a quaterpyridine. For example, $4^{\prime}$ (pyridin-2-yl)-2,2': $: 6^{\prime}, 2^{\prime \prime}$-tpy contains a $2,2^{\prime}: 4^{\prime}, 2^{\prime \prime}$-tpy unit (Scheme 2a), but typically coordinates through the $2,2^{\prime}: 6^{\prime}, 2^{\prime \prime}$-tpy unit and is best considered as a $4^{\prime}$-functionalized $2,2^{\prime}: 6^{\prime}, 2^{\prime \prime}$-tpy. Similarly, the $4,2^{\prime}: 4^{\prime}, 4^{\prime \prime}$-tpy motif is present in $4^{\prime}$-(pyridin-4-yl)-4,2' $: 6^{\prime}, 4^{\prime \prime}$ tpy and all three modes of coordination shown in Scheme $2 b$ are represented in the CSD.

The seminal work of Fujita includes $\left[\mathrm{Pd}_{6}(\mathrm{en})_{6}\left(3,3^{\prime}: 5^{\prime}, 3^{\prime \prime} \text {-tpy }\right)_{4}\right]^{12+}$ and $\left[\operatorname{Pd}_{6}(\text { bpy })_{6}\left(4,3^{\prime}: 5^{\prime}, 4^{\prime \prime} \text {-tpy }\right)_{4}\right]^{12+}$ metallocages, ${ }^{11,12}$ but no
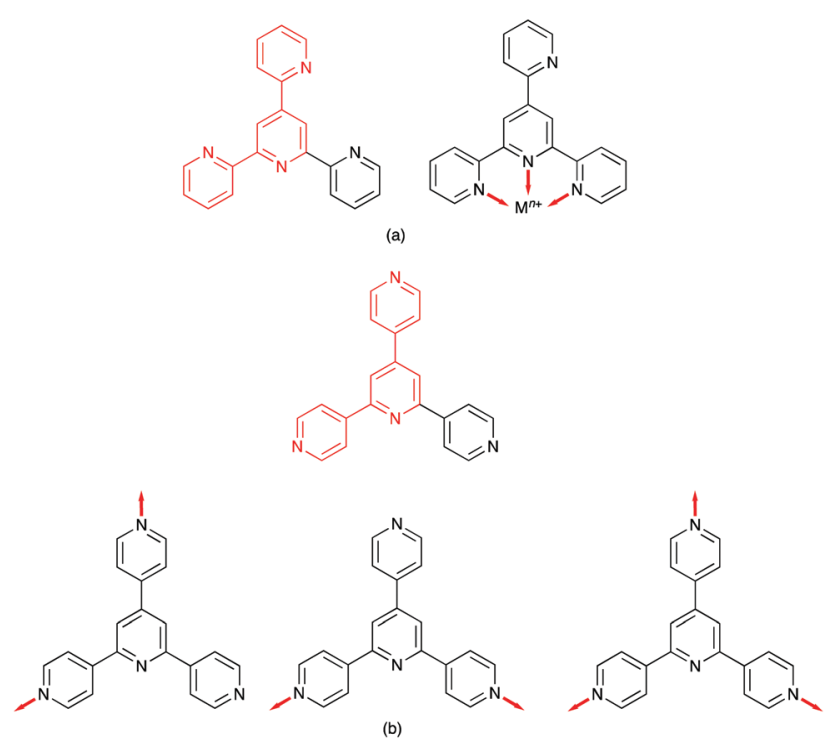

Scheme 2 Examples of tpy motifs as units within quaterpyridines. (a) $4^{\prime}$ (Pyridin-2-yl)-2, $2^{\prime}: 6^{\prime}, 2^{\prime \prime}$-tpy contains a $2,2^{\prime}: 4^{\prime}, 2^{\prime \prime}$-tpy unit (in red) but typically binds metal ions as a bis(chelate). (b) 4'-(Pyridin-4-yl)$4,2^{\prime}: 6^{\prime}, 4^{\prime \prime}$-tpy contains a $4,2^{\prime}: 4^{\prime}, 4^{\prime \prime}$-tpy unit (in red); three possible ditopic modes of bonding of $4^{\prime}$-(pyridin-4-yl)- $4,2^{\prime}: 6^{\prime}, 4^{\prime \prime}$-tpy represented in the CSD by refcode entries AGUPUO (left), QOTREY (middle) and RIGPII (right).

structurally characterized extended assemblies involving $3,3^{\prime}: 5^{\prime}, 3^{\prime \prime}$-tpy (Scheme 1) are present in the CSD. Several 1D-coordination polymers and 2D-networks incorporating $4,3^{\prime}: 5^{\prime}, 4^{\prime \prime}$-tpy are known, and either all three, ${ }^{13,14}$ or only the outer pyridine rings $\mathrm{s}^{13-17}$ may be involved in coordination. Note that, in terms of the vectorial properties of the outer pyridine nitrogen lone pairs, $4,3^{\prime}: 5^{\prime}, 4^{\prime \prime}$-tpy and $3,3^{\prime}: 5^{\prime}, 3^{\prime \prime}$-tpy are analogous to $4,2^{\prime}: 6^{\prime}, 4^{\prime \prime}$-tpy and $3,2^{\prime}: 6^{\prime}, 3^{\prime \prime}$-tpy (Scheme 1). [ $\mathrm{Fe}\left(4,2^{\prime}: 5^{\prime}, 4^{\prime \prime}\right.$ tpy) $\left.\left\{\mathrm{Au}(\mathrm{CN})_{2}\right\}_{2}\right]_{n}$ is the sole example of a coordination network containing $4,2^{\prime}: 5^{\prime}, 4^{\prime \prime}$-tpy (Scheme 1).$^{18}$ Noteworthy points are that the vectorial properties of $4,2^{\prime}: 5^{\prime}, 4^{\prime \prime}$-tpy mimic those of $4,4^{\prime}$ bipyridine (a rigid rod linker), and that the central pyridine ring is non-coordinating. This last observation is a recurring theme in the coordination chemistry of $4,2^{\prime}: 6^{\prime}, 4^{\prime \prime}$-tpy and $3,2^{\prime}: 6^{\prime}, 3^{\prime \prime}$-tpy as later examples show. In contrast, $2,2^{\prime}: 5^{\prime}, 4^{\prime \prime}$-tpy (Scheme 1) offers a 
chelating 2,2'-bipyridine domain and one pendant pyridine donor as seen in $\left\{\left[\mathrm{Cu}\left(2,2^{\prime}: 5^{\prime}, 4^{\prime \prime} \text {-tpy }\right)(\mathrm{MeCN})\right]\left(\mathrm{BF}_{4}\right)\right\}_{n},\left\{\left[\mathrm{Cu}\left(2,2^{\prime}: 5^{\prime}, 4^{\prime \prime}-\right.\right.\right.$ tpy)(MeCN) $\left.]\left(\mathrm{PF}_{6}\right)\right\}_{n}$ and $\left\{\left[\mathrm{Cu}\left(2,2^{\prime}: 5^{\prime}, 4^{\prime \prime} \text {-tpy }\right)(\mathrm{MeCN})\right]\left(\mathrm{NO}_{3}\right)\right\}_{n} \cdot{ }^{19}$ These are the only examples in the CSD of coordination polymers containing $2,2^{\prime}: 5^{\prime}, 4^{\prime \prime}$-tpy.

\section{Ligands with $4,2^{\prime}: 6^{\prime}, 4^{\prime \prime}$-tpy and $3,2^{\prime}: 6^{\prime}, 3^{\prime \prime}$-tpy metal binding domains}

There are no (as of June 2020) structurally confirmed examples of metal complexes of $4,2^{\prime}: 6^{\prime}, 4^{\prime \prime}$-tpy and $3,2^{\prime}: 6^{\prime}, 3^{\prime \prime}$-tpy ligands in which the central pyridine ring binds a metal ion. Hence the $4,2^{\prime}: 6^{\prime}, 4^{\prime \prime}$-tpy and $3,2^{\prime}: 6^{\prime}, 3^{\prime \prime}$-tpy ligands drawn in Scheme 1 are considered to be ditopic. This ignores the possibility of hypodenticity. ${ }^{3}$ The connection of two $4,2^{\prime}: 6^{\prime}, 4^{\prime \prime}$-tpy or $3,2^{\prime}: 6^{\prime}, 3^{\prime \prime}$-tpy metal-binding domains by an organic spacer generates a tetratopic ligand (Scheme 3). To date, extended coordination assemblies have employed only ditopic ${ }^{20}$ and

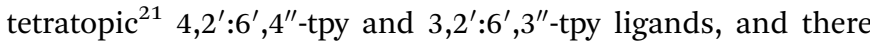
is significant scope for investigations of building blocks incorporating additional metal-binding domains similar to the strategy adopted for $2,2^{\prime}: 6^{\prime}, 2^{\prime \prime}$-tpy in ligands such as 1,3,5$\operatorname{tris}\left(2,2^{\prime}: 6^{\prime}, 2^{\prime \prime}\right.$-terpyridin-4'-yl)benzene. ${ }^{22}$

Central to the development of the coordination chemistry of $4,2^{\prime}: 6^{\prime}, 4^{\prime \prime}$-tpy and $3,2^{\prime}: 6^{\prime}, 3^{\prime \prime}$-tpy ligands is an appreciation of their conformational flexibility and how this can influence their spatial properties. Both $4,2^{\prime}: 6^{\prime}, 4^{\prime \prime}$-tpy and $3,2^{\prime}: 6^{\prime}, 3^{\prime \prime}$-tpy can rotate about the inter-ring $\mathrm{C}-\mathrm{C}$ bonds. For $4,2^{\prime}: 6^{\prime}, 4^{\prime \prime}$-tpy, this leads to no change in the directional properties of the nitrogen lone pairs, as shown for the ditopic $4,2^{\prime}: 6^{\prime}, 4^{\prime \prime}$-tpy and tetratopic bis $\left(4,2^{\prime}: 6^{\prime}, 4^{\prime \prime}\right.$-tpy) ligands in Scheme 3 . In contrast, inter-ring

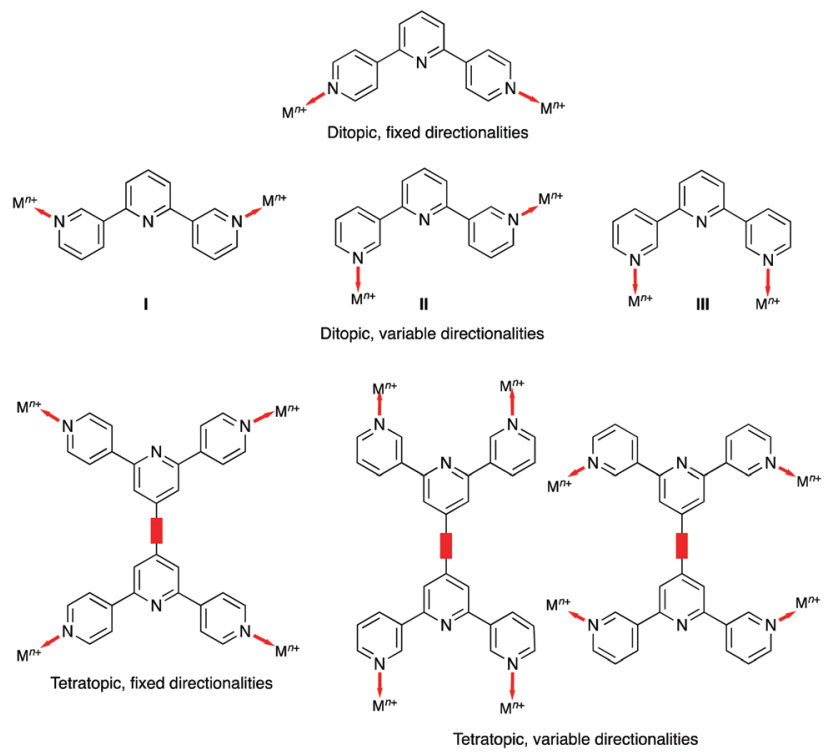

Scheme 3 Rotation about the inter-ring $C-C$ bonds makes no difference to the directionality of the nitrogen lone pairs in $4,2^{\prime}: 6^{\prime}, 4^{\prime \prime}$-tpy metalbinding domains, but does affect the directional properties of $3,2^{\prime}: 6^{\prime}, 3^{\prime \prime}$ tpy metal-binding domains. For the tetratopic bis $\left(3,2^{\prime}: 6^{\prime}, 3^{\prime \prime}\right.$-tpy) ligand, only two examples of different directionalities are shown. The red spacer in the tetratopic ligands represents any organic linker.
$\mathrm{C}-\mathrm{C}$ bond rotation affects the spatial properties of the nitrogen lone pairs in 3,2': $6^{\prime}, 3^{\prime \prime}$-tpy (Scheme 3), and it has been observed that the conformations of both free and coordinated $3,2^{\prime}: 6^{\prime}, 3^{\prime \prime}$ tpy ligands respond to changes in crystal packing. ${ }^{23-25}$

The first $4,2^{\prime}: 6^{\prime}, 4^{\prime \prime}$-tpy containing coordination polymer, $2\left[\mathrm{ZnCl}_{2}\left(4,2^{\prime}: 6^{\prime}, 4^{\prime \prime} \text {-tpy }\right)\right]_{n}$, was described over 20 years ago by González Garmendia and coworkers, ${ }^{26}$ and remains the sole example of a structurally characterized extended assembly containing the unfunctionalized $4,2^{\prime}: 6^{\prime}, 4^{\prime \prime}$-tpy ligand. Use of the Wang and Hanan, ${ }^{7}$ and the Kröhnke ${ }^{8}$ strategies provides access to a large suite of $4^{\prime}$-functionalized $4,2^{\prime}: 6^{\prime}, 4^{\prime \prime}$-tpy and $3,2^{\prime}: 6^{\prime}, 3^{\prime \prime}$-tpy ligands, and in the last decade, the number of 1D-, 2D- and 3D-coordination assemblies incorporating such ligands has increased significantly. ${ }^{27-30}$ However, systematic investigations are somewhat lacking, and are undoubtedly needed in order to better understand the assembly algorithms. We have focused especially on introducing $4^{\prime}$-alkyloxy substituents, and in an early investigation, ${ }^{31}$ we demonstrated a switch from $1 \mathrm{D}$-coordination polymers $\left[\mathrm{Zn}_{2}(\mu-\mathrm{OAc})_{4}\left\{4^{\prime}-(4-\right.\right.$ alkyloxyphenyl)-4,2': $: 6^{\prime}, 4^{\prime \prime}$-tpy $\left.\}\right]_{n}$ (alkyl = methyl, ethyl, ${ }^{n}$ propyl) to discrete $\left[\mathrm{Zn}_{2}(\mu-\mathrm{OAc})_{4}\left\{4^{\prime} \text {-(4-alkyloxyphenyl)-4,2' }: 6^{\prime}, 4^{\prime \prime} \text {-tpy }\right\}_{2}\right]$ complexes (alkyl $=n$-octyl, $n$-nonyl, $n$-decyl) as van der Waals interactions between $n$-alkyloxy chains in extended conformations became dominant packing forces in the crystal lattice. These observations motivated the further systematic studies discussed below.

Competition between assembly processes under the same crystallization conditions and, often, in the same crystallization tube, is also little understood, ${ }^{32-35}$ and we are far from understanding the interplay between thermodynamic and kinetic products during crystallization processes. The use of solvent diffusion methods results in crystallization conditions far from equilibrium. In the following discussion, we focus on our recent systematic studies of $2 \mathrm{D}$ - and $3 \mathrm{D}$-coordination network assembly using $4^{\prime}$-functionalized $4,2^{\prime}: 6^{\prime}, 4^{\prime \prime}$-tpy and $3,2^{\prime}: 6^{\prime}, 3^{\prime \prime}$ tpy ligands, and assess the extent to which the outcome of a reaction between a given combination of metal salt and ligand is predictable. In our own work, all crystal growth experiments have been carried out under ambient conditions using layering techniques. We note that, in the interests of clarity in this article, solvent molecules in structural formulae are not explicitly included.

\section{Going from a 1D-coordination polymer to 2D-networks}

An extended coordination assembly is typically described in terms of nodes and linkers and three limiting scenarios are identified: (i) metal node and organic ligand linker, (ii) ligand node and metal linker, or (iii) metal and ligand nodes. A linker connects two nodes together. Without additional donors, as illustrated in Scheme $2 \mathrm{~b}$, ditopic $4,2^{\prime}: 6^{\prime}, 4^{\prime \prime}$-tpy and $3,2^{\prime}: 6^{\prime}, 3^{\prime \prime}$-tpy are limited to roles as linkers. Thus, reactions with $\mathrm{ZnX}_{2}\left(\mathrm{X}^{-}=\mathrm{OAc}^{-}\right.$, $\left.\mathrm{Cl}^{-}, \mathrm{Br}^{-}, \mathrm{I}^{-}\right)$produce 1D-polymers and/or metallomacrocycles. ${ }^{27,28}$ Two strategies to increase the dimensionality are to choose a metal which favours a coordination number of six or higher, or to use ligands with two or more $4,2^{\prime}: 6^{\prime}, 4^{\prime \prime}$-tpy and $3,2^{\prime}: 6^{\prime}, 3^{\prime \prime}$-tpy domains. 
Table 1 Summary of $\left[\mathrm{Co}(\mathrm{NSC})_{2}\left(4,2^{\prime}: 6^{\prime}, 4^{\prime \prime}-\mathrm{tpy}\right)_{2}\right]_{n}$ and $\left[\mathrm{Co}(\mathrm{NSC})_{2}\left(3,2^{\prime}: 6^{\prime}, 3^{\prime \prime}-\right.\right.$ tpy) 2$]_{n}$ 2D-networks

\begin{tabular}{|c|c|c|c|c|}
\hline $4^{\prime}$-Substituent & Refcode $^{a}$ & Space group & $\begin{array}{l}\text { Net type depicted } \\
\text { in Fig. } 2\end{array}$ & Ref. \\
\hline \multicolumn{5}{|l|}{$4,2^{\prime}: 6^{\prime}, 4^{\prime \prime}$-tpy } \\
\hline${ }^{t} \mathrm{Bu}$ & FAKRIU $^{b}$ & $C 2$ & $(4,4)$ type 1 & 36 \\
\hline${ }^{t} \mathrm{Bu}$ & ZUNJUP $^{b}$ & $C 2 / c$ & $(4,4)$ type 1 & 37 \\
\hline $\mathrm{Ph}$ & ZAWMAN & $C 2 / c$ & $(4,4)$ type 1 & 38 \\
\hline Ferrocen-1-yl & REPHOM & $P 2_{1} / n$ & $(4,4)$ type 1 & 33 \\
\hline $1 H$-Imidazol-4-yl & ZAWLIU & $P 2_{1} / c$ & $(4,4)$ type 1 & 39 \\
\hline $4-\mathrm{HC} \equiv \mathrm{CC}_{6} \mathrm{H}_{4}{ }^{2}$ & ZAWLOA & $C 2 / c$ & $(6,3)$ & 39 \\
\hline $4-\mathrm{MeOC}_{6} \mathrm{H}_{4}$ & ISOHUV $^{b}$ & $P 2_{1} / c$ & $(4,4)$ type 1 & 40 \\
\hline $4-\mathrm{MeOC}_{6} \mathrm{H}_{4}$ & ZUNJOJ $^{b}$ & $P \overline{1}$ & $(4,4)$ type 1 & 37 \\
\hline 4 -EtOC ${ }_{6} \mathrm{H}_{4}$ & ZUNKAW & $P 2_{1} / n$ & $(4,4)$ type 1 & 37 \\
\hline $4-{ }^{n} \mathrm{PrOC}_{6} \mathrm{H}_{4}$ & ZUNKEA & $P 2_{1} / n$ & $(4,4)$ type 1 & 37 \\
\hline \multicolumn{5}{|l|}{$3,2^{\prime}: 6^{\prime}, 3^{\prime \prime}$-tpy } \\
\hline $4-\mathrm{MeOC}_{6} \mathrm{H}_{4}$ & FOXQUH $^{b}$ & $P 2_{1} / n$ & $(4,4)$ type 1 & 34 \\
\hline $4-\mathrm{MeOC}_{6} \mathrm{H}_{4}$ & FOXRAO $^{b}$ & $P 2_{1} / c$ & $(4,4)$ type 1 & 34 \\
\hline 4 -EtOC ${ }_{6} \mathrm{H}_{4}$ & OHESAY & $P 4 / n c c$ & $(4,4)$ type 2 & 25 \\
\hline $4-{ }^{n} \mathrm{PrOC}_{6} \mathrm{H}_{4}$ & OHESIG & $P \overline{4} 2_{1} c$ & $(4,4)$ type 2 & 25 \\
\hline $4-{ }^{n} \mathrm{BuOC}_{6} \mathrm{H}_{4}$ & OHESOM & $P \overline{4} 2_{1} c$ & $(4,4)$ type 2 & 25 \\
\hline $4-{ }^{n} \mathrm{PeOC}_{6} \mathrm{H}_{4}$ & OHERUR & $P 2_{1} / n$ & $(4,4)$ type 1 & 25 \\
\hline $4-{ }^{n} \mathrm{HxOC}_{6} \mathrm{H}_{4}$ & OHESEC & $P 2_{1} / c$ & $(4,4)$ type 1 & 25 \\
\hline
\end{tabular}

${ }^{a}$ CSD refcode. ${ }^{b}$ Compounds with the same $4^{\prime}$-substituent differ in the solvent of crystallization.

Let us first consider the metal-node/ligand-linker approach. In our investigations of 2D- and 3D-networks involving ditopic isomers of terpyridine, we have focused on reactions with $\mathrm{Co}(\mathrm{NCS})_{2}$ and $\mathrm{Cd}\left(\mathrm{NO}_{3}\right)_{2}$. Although both metal(II) ions favour a 6-coordinate geometry, $\mathrm{Cd}(\mathrm{II})\left(\mathrm{d}^{10}\right)$ can also exhibit higher coordination numbers. Furthermore, the $N$-bonded thiocyanato ligands in cobalt(III) complexes typically coordinate in a transarrangement leaving four vacant coordination sites in the equatorial plane of an octahedral coordination sphere. It follows that reactions of $\mathrm{Co}(\mathrm{NCS})_{2}$ with either $4,2^{\prime}: 6^{\prime}, 4^{\prime \prime}$ - or $3,2^{\prime}: 6^{\prime}, 3^{\prime \prime}$-tpy ligands (in the absence of coordinatively noninnocent $4^{\prime}$-functionalities) tend to produce $(4,4)$ nets.

Table 1 and Fig. 2 summarize $\left[\mathrm{Co}(\mathrm{NSC})_{2}\left(4,2^{\prime}: 6^{\prime}, 4^{\prime \prime}-\text { tpy }\right)_{2}\right]_{n}$ and $\left[\mathrm{Co}(\mathrm{NSC})_{2}\left(3,2^{\prime}: 6^{\prime}, 3^{\prime \prime} \text {-tpy }\right)_{2}\right]_{n}$ networks. In all structures, the Co atoms are in trans $-\left\{\mathrm{Co}(\mathrm{NCS})_{2} \mathrm{~N}_{4}\right\}$ environments and, with one exception, all are the expected $(4,4)$ nets with one ditopic ligand bridging two $\mathrm{Co}$ (II) centres. Although all these nets are topologically identical, crystal symmetry distinguishes between

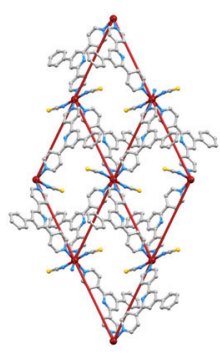

(a)

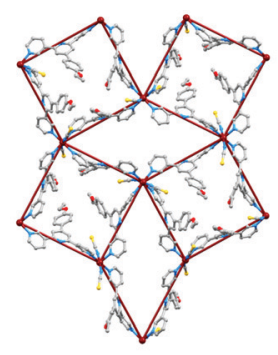

(b)

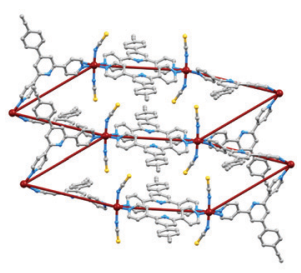

(c)
Fig. 2 2D-networks found in $\left[\mathrm{Co}(\mathrm{NSC})_{2}\left(4,2^{\prime}: 6^{\prime}, 4^{\prime \prime}-\mathrm{tpy}\right)_{2}\right]_{n}$ and $\left[\mathrm{Co}(\mathrm{NSC})_{2}\right.$ $\left(3,2^{\prime}: 6^{\prime}, 3^{\prime \prime} \text {-tpy) }\right]_{n}$ in which the ligands bear $4^{\prime}$-substituents (see Table 1 ): (a) $(4,4)$ type 1 (e.g. CSD refcode ZAWMAN), (b) $(4,4)$ type 2 (e.g. refcode OHESAY), and (c) $(6,3)$ (refcode ZAWLOA). $\mathrm{H}$ atoms omitted. the nets labelled types 1 and 2 in Fig. $2 \mathrm{a}$ and b, respectively. When the ligand is $4^{\prime}-\left(4-\mathrm{HC} \equiv \mathrm{CC}_{6} \mathrm{H}_{4}\right)-4,2^{\prime}: 6^{\prime}, 4^{\prime \prime}$-tpy, the assembly switches to a $(6,3)$ net with adjacent Co nodes bridged by either one or two ligands as shown in Fig. 2c. The reason for this departure from the more typical $(4,4)$ network is not clear, but a contributing factor may be the role of $\mathrm{C} \equiv \mathrm{C}-\mathrm{H} \cdots \mathrm{S}$ contacts involving $\mathrm{C} \equiv \mathrm{C}-\mathrm{H}$ and $\mathrm{SCN}$ units in adjacent sheets. $^{39}$ The S $\cdots H$ distance of $2.69 \AA$ is well within the sum of the van der Waals radii of $\mathrm{S}(1.85 \AA)$ and $\mathrm{H}\left(1.20 \AA\right.$ Bondi, ${ }^{41}$ or $1.10 \AA$ Rowland and Taylor ${ }^{42}$ ). As discussed earlier, the conformational flexibility of the $3,2^{\prime}: 6^{\prime}, 3^{\prime \prime}$-tpy domain allows it to adapt to changes in the $4^{\prime}$-functionality, and this is nicely illustrated in the series of [Co(NSC $)_{2}\left\{4^{\prime}-(4-n\right.$-alkyloxyphenyl)$3,2^{\prime}: 6^{\prime}, 3^{\prime \prime}-$ tpy $\left._{2}\right]_{n}$ networks. For the 4 -EtOC ${ }_{6} \mathrm{H}_{4}, 4{ }^{n}{ }^{n} \mathrm{PrOC}_{6} \mathrm{H}_{4}$ and $4-{ }^{n} \mathrm{BuOC}_{6} \mathrm{H}_{4}$ substituents, the nets pack with cone-like arrangements of $n$-alkyloxyphenyl groups accommodated within cone-shaped cavities in an adjacent net (Fig. 3a). While the $(4,4)$ type 1 net (Fig. $2 \mathrm{a}$ ) is common to [Co(NSC) ${ }_{2}\left\{4^{\prime}-(4-n\right.$ alkyloxyphenyl)-3,2' $: 6^{\prime}, 3^{\prime \prime}$-tpy $\left.\}_{2}\right]_{n}$ with $4-\mathrm{MeOC}_{6} \mathrm{H}_{4}, 4{ }^{n}{ }^{n} \mathrm{PeOC}_{6} \mathrm{H}_{4}$ and $4-{ }^{n} \mathrm{HxOC}_{6} \mathrm{H}_{4}$ groups, the arrangement of the sheets differs. Eclipsed networks are observed in $\left[\mathrm{Co}(\mathrm{NSC})_{2}\left\{4^{\prime}-\left(4-\mathrm{MeOC}_{6} \mathrm{H}_{4}\right)-\right.\right.$ $3,2^{\prime}: 6^{\prime}, 3^{\prime \prime}$-tpy $\left.\}_{2}\right]_{n}$, while an $\mathrm{ABAB} \cdots$ arrangement of sheets in $\left[\mathrm{Co}(\mathrm{NSC})_{2}\left\{4^{\prime}-\left(4{ }^{n}{ }^{n} \mathrm{PeOC}_{6} \mathrm{H}_{4}\right)-3,2^{\prime}: 6^{\prime}, 3^{\prime \prime}-\mathrm{tpy}\right\}_{2}\right]_{n}$ and $\left[\mathrm{Co}(\mathrm{NSC})_{2}\left\{4^{\prime}-\right.\right.$ $\left(4{ }^{n}{ }^{-} \mathrm{HxOC}_{6} \mathrm{H}_{4}\right)-3,2^{\prime}: 6^{\prime}, 3^{\prime \prime}$-tpy $\left.\}_{2}\right]_{n}$ allows the longer chains to be accommodated in cavities in adjacent sheets (Fig. 3b). ${ }^{25,34}$ The sheets also move further apart; the distance between the mean planes through the Co atoms in a sheet is $9.1 \AA$ in $\left[\mathrm{Co}(\mathrm{NSC})_{2}\left\{4^{\prime}\right.\right.$ $\left(4-\mathrm{EtOC}_{6} \mathrm{H}_{4}\right)-3,2^{\prime}: 6^{\prime}, 3^{\prime \prime}$-tpy $\left.\}_{2}\right]_{n}$ and $10.7 \AA$ in $\left[\mathrm{Co}\left(\mathrm{NSC}_{2}\left\{4^{\prime}\right.\right.\right.$ $\left.\left.\left(4-{ }^{n} \mathrm{HxOC}_{6} \mathrm{H}_{4}\right)-3,2^{\prime}: 6^{\prime}, 3^{\prime \prime}-\mathrm{tpy}\right\}_{2}\right]_{n}$.

The need to combine single crystal structural determinations with powder X-ray diffraction (PXRD) to confirm the structural integrity of the bulk material is critical. A pertinent example comes from the reaction of $\mathrm{Co}(\mathrm{NCS})_{2}$ with $4^{\prime}-(4-$ $\left.\mathrm{MeOC}_{6} \mathrm{H}_{4}\right)-3,2^{\prime}: 6^{\prime}, 3^{\prime \prime}$-tpy. As seen above (Table 1), the anticipated $(4,4)$ network does form, but the assembly process under conditions of layering a $\mathrm{MeOH}$ solution of $\mathrm{Co}(\mathrm{NCS})_{2}$ over a $\mathrm{CHCl}_{3}$ solution of ligand is not simple. Depending upon the period of crystallization, and the zone within the crystallization tube, both 2D-networks (pseudopolymorphs differing in solvate) and a $1 \mathrm{D}$-coordination polymer $\left[\mathrm{Co}(\mathrm{NCS})_{2}(\mathrm{MeOH})_{2}\left\{4^{\prime}-\right.\right.$ (4- $\left.\mathrm{MeOC}_{6} \mathrm{H}_{4}\right)-3,2^{\prime}: 6^{\prime}, 3^{\prime \prime}$-tpy\} $]_{n}$ (Fig. 4) can be isolated from the reactions. Importantly, PXRD confirmed that the dominant product in the bulk samples was the 1D-coordination polymer. ${ }^{34}$ Significantly, we have reported similar 1D-polymer formation in

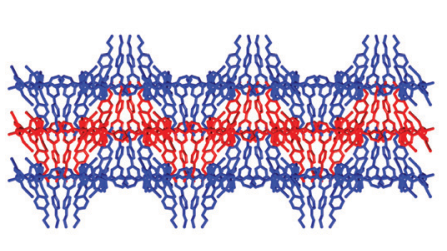

(a)

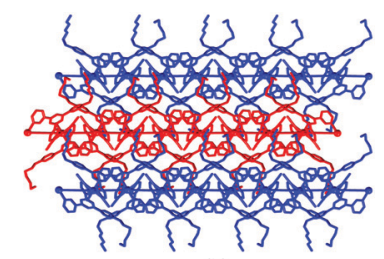

Fig. 3 Packing of $(4,4)$ nets in (a) [Co(NSC) ${ }_{2}\left\{4^{\prime}-\left(4-E^{-E_{O}}{ }_{6} \mathrm{H}_{4}\right)-3,2^{\prime}: 6^{\prime}, 3^{\prime \prime}-\right.$ tpy $\left.\}_{2}\right]_{n}$ (CSD refcode OHESAY) and (b) $\left[\mathrm{Co}(\mathrm{NSC})_{2}\left\{4^{\prime}-\left(4-{ }^{n} \mathrm{HxOC}_{6} \mathrm{H}_{4}\right)-\right.\right.$ $3,2^{\prime}: 6^{\prime}, 3^{\prime \prime}-$ tpy $\left.\}_{2}\right]_{n}$ (CSD refcode OHESEC). $\mathrm{H}$ atoms omitted. 


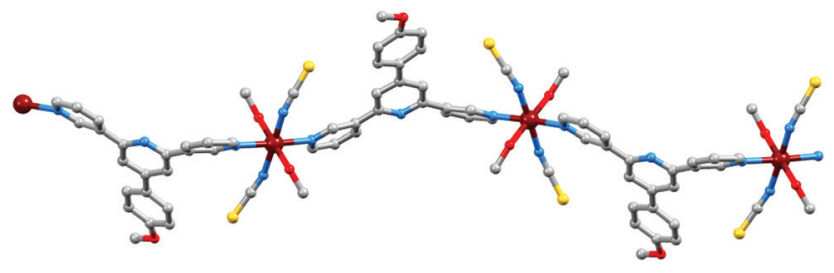

Fig. 4 The formation of the $1 \mathrm{D}$-coordination polymer $\left[\mathrm{Co}(\mathrm{NCS})_{2}(\mathrm{MeOH})_{2}\right.$ $\left\{4^{\prime}-\left(4-\mathrm{MeOC}_{6} \mathrm{H}_{4}\right)-3,2^{\prime}: 6^{\prime}, 3^{\prime \prime} \text {-tpy\} }\right]_{n}$ (CSD refcode FOXRES) competes with the assembly of the 2D-network [Co(NSC) ${ }_{2}\left\{4^{\prime}-\left(4-\mathrm{MeOC}_{6} \mathrm{H}_{4}\right)-3,2^{\prime}: 6^{\prime}, 3^{\prime \prime}-\right.$ tpy $\left.\}_{2}\right]_{n} . \mathrm{H}$ atoms omitted.

reactions of $\mathrm{Co}(\mathrm{NCS})_{2}$ with $4^{\prime}-\left(4-\mathrm{Me}_{2} \mathrm{NC}_{6} \mathrm{H}_{4}\right)-3,2^{\prime}: 6^{\prime}, 3^{\prime \prime}$-tpy, ${ }^{39}$ and $4^{\prime}$-(2-methylpyrimidin-5-yl)-4, $2^{\prime}: 6^{\prime}, 4^{\prime \prime}$-terpyridine. ${ }^{33}$

\section{Ligands as 4-connecting nodes}

In the discussion above, we saw how structural perturbation of 2D-networks assembled using $\mathrm{Co}(\mathrm{NCS})_{2}$ and $4,2^{\prime}: 6^{\prime}, 4^{\prime \prime}$ - or $3,2^{\prime}: 6^{\prime}, 3^{\prime \prime}$-tpy linkers can be induced by changes in the $4^{\prime}$ substituent of the ligands, in particular by varying the length of an $n$-alkyloxy chain. In our investigations of the tetratopic ligands depicted in Scheme 3, we initially used arene spacers between the two terpyridine metal-binding domains. To increase ligand solubility, we introduced $n$-alkyloxy substituents (Scheme 4), and observed that the length of the chain had a profound effect on network assembly. In contrast to the ditopic ligands discussed in the previous section which act as linkers in coordination assemblies, the tetratopic ligands 1-11 function as 4-connecting nodes. Thus, of the three assembly strategies listed in the previous section, ligands 1-11 are suited for combination with either metal linkers or metal nodes.

\section{Ligand-node/metal-linker strategy: $2 \mathrm{D} \rightarrow 2 \mathrm{D}$ parallel interpenetration versus simple 2D-networks}

Initial explorations of the coordination chemistry of these tetratopic ligands involved reactions of 1, 4, 5 and 6 with zinc(II) halides $\left(\mathrm{ZnX}_{2}\right)$ following the ligand-node/metal-linker strategy. Reactions of 1 with $\mathrm{ZnX}_{2}$ resulted in $(4,4)$-nets $\left[\mathrm{Zn}_{2} \mathrm{X}_{4}(\mathbf{1})\right]_{n}$ (Fig. 5a). As Fig. 5b illustrates, the methoxy substituents are directed above and below the mean plane through the ligand nodes and, apparently, play little role in directing the assembly. ${ }^{43}$ In contrast, the longer $n$-hexyloxy, $n$-octyloxy and

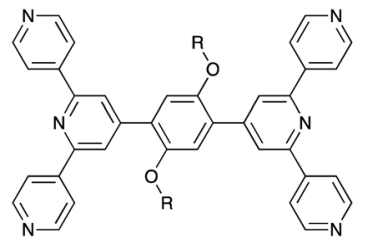

$$
\begin{array}{ll}
1 & \mathrm{R}=\text { methyl } \\
2 & \mathrm{R}=n \text {-propyl } \\
3 & \mathrm{R}=n \text {-pentyl } \\
4 & \mathrm{R}=n \text {-hexyl } \\
5 & \mathrm{R}=n \text {-octyl } \\
6 & \mathrm{R}=n \text {-decyl } \\
7 & \mathrm{R}=3 \text {-phenylpropyl }
\end{array}
$$

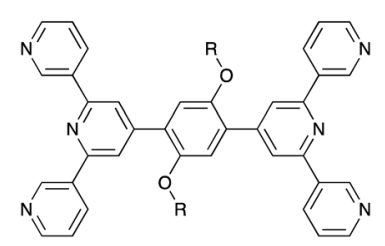

$8 \mathrm{R}=n$-octyl

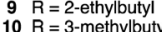

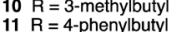

Scheme 4 Structures of tetratopic ligands with $4,2^{\prime}: 6^{\prime}, 4^{\prime \prime}$-tpy domains (left) and $3,2^{\prime}: 6^{\prime}, 3^{\prime \prime}$-tpy domains (right).

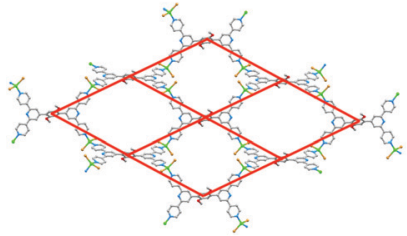

(a)

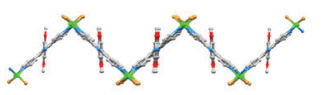

(b)

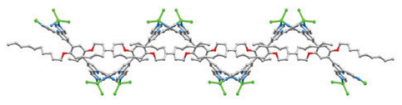

(c)

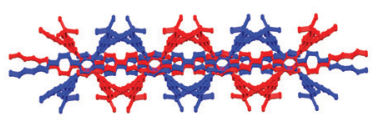

(d)

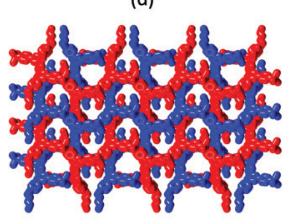

(e)
Fig. 5 (a) Part of the $(4,4)$-net in $\left[\mathrm{Zn}_{2} \mathrm{Br}_{4}(\mathbf{1})\right]_{n}$ (CSD refcode ZUGVII, $\mathrm{H}$ atoms omitted); ligand $\mathbf{1}$ is a 4 -connecting node. (b) The same net viewed through the mean plane through the ligand nodes showing the orientation of the $\mathrm{MeO}$ groups above and below the plane. (c) Part of one $(4,4)$-net in $\left[\mathrm{Zn}_{2} \mathrm{Cl}_{4}(6)\right]_{n}$ (CSD refcode DAQMIU, $\mathrm{H}$ atoms omitted) and (d) and (e) two views of $2 \mathrm{D} \rightarrow 2 \mathrm{D}$ parallel interpenetrated nets in $\left[\mathrm{Zn}_{2} \mathrm{Cl}_{4}(\mathbf{6})\right]_{n}$.

$n$-decyloxy chains extend through the plane of the $(4,4)$ net as shown for $\left[\mathrm{Zn}_{2} \mathrm{Cl}_{4}(6)\right]_{n}$ in Fig. $5 \mathrm{c}$. While retaining the corrugated form of the $(4,4)$ nets in $\left[\mathrm{Zn}_{2} \mathrm{X}_{4}(\mathbf{1})\right]_{n}$, the nets containing ligands 4,5 and 6, are more open, leading to $2 \mathrm{D} \rightarrow 2 \mathrm{D}$ parallel interpenetration (Fig. 5d and e). ${ }^{43-45}$ We have proposed that long $n$-alkyloxy chains are essential for directing this assembly, and it is significant that the profile of the net (Fig. 5c) and the unit cell parameters (Table 2) change little on going from $n$-hexyloxy to $n$-decyloxy, and that the chains consistently adopt extended conformations (Fig. $5 \mathrm{c}$ and $\mathrm{d}$ ).

Ligand-node/metal-linker strategy: an aryl substituent makes a difference

Given the persistence of the $2 \mathrm{D} \rightarrow 2 \mathrm{D}$ parallel interpenetrated nets for reactions of $\mathrm{ZnX}_{2}$ with bis $\left(4,2^{\prime}: 6^{\prime}, 4^{\prime \prime}\right.$-tpy) ligands containing $n$-alkyloxy chains, we were interested to explore the effects of introducing a terminal phenyl group to the chain. We argued that, not only should this perturb the threading of the alkyloxy chains through the lattice, it should also introduce the potential for additional $\pi$-stacking interactions. We selected the 3-phenylpropoxy chain (ligand 7, Scheme 4) because it was similar in length to the $n$-hexyloxy chain in $\mathbf{4}$ allowing a reasonable comparison of network assemblies. Crystal growth by layering solutions of 7 and $\mathrm{ZnBr}_{2}$ yielded $\left[\mathrm{Zn}_{2} \mathrm{Br}_{4}(7)\right]_{n}$. We note that (as in a number of the 3D-networks that we discuss in the following sections) SQUEEZE ${ }^{46}$ had to be applied to the solvent region. In the case of $\left[\mathrm{Zn}_{2} \mathrm{Br}_{4}(7)\right]_{n}$ it was not possible to

Table 2 Unit cell parameters for 2D $\rightarrow 2 \mathrm{D}$ parallel interpenetrated nets of type $\left[\mathrm{Zn}_{2} \mathrm{X}_{4}(\mathrm{~L})\right]_{n}$

\begin{tabular}{lllllll}
\hline $\mathbf{L}$ & $\mathrm{X}$ & Space group & $a / \AA$ & $b / \AA$ & $c / \AA$ & $\beta / \mathrm{deg}$ \\
\hline $\mathbf{4}$ & $\mathrm{Cl}$ & $C 2 / c$ & $20.4985(9)$ & $11.6491(3)$ & $23.7457(10)$ & $91.737(4)$ \\
$\mathbf{5}$ & $\mathrm{Cl}$ & $C 2 / c$ & $20.6102(6)$ & $11.5999(6)$ & $23.8198(12)$ & $90.978(3)$ \\
$\mathbf{5}$ & $\mathrm{Br}$ & $C 2 / c$ & $20.6639(16)$ & $11.9145(10)$ & $23.6388(17)$ & $92.289(5)$ \\
$\mathbf{6}$ & $\mathrm{Cl}$ & $C 2 / c$ & $20.777(2)$ & $11.6382(9)$ & $23.8738(17)$ & $90.074(7)$
\end{tabular}




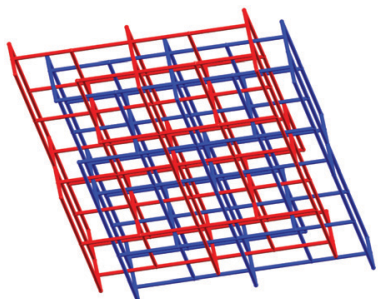

(a)

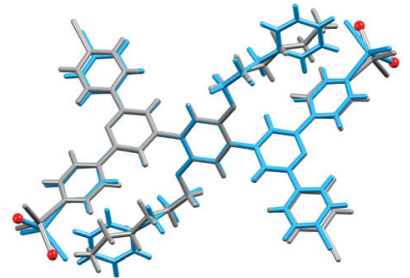

(b)
Fig. 6 (a) Interpenetrating nbo networks in $\left[\mathrm{Zn}_{2} \mathrm{Br}_{4}(7)\right]_{n}$ (CSD refcode DAQMAM, TOPOS ${ }^{49}$ representation). (b) Overlay of the repeat units with symmetry generated atoms of $\left[\mathrm{Zn}_{2} \mathrm{Cl}_{4}(6)\right]_{n}$ (in grey, CSD refcode DAQMEQ) and $\left[\mathrm{Zn}_{2} \mathrm{Cl}_{4}(\mathbf{7})\right]_{n}$ (in cyan); the positions of symmetry-generated $\mathrm{N}$ atoms which dictate the direction of network propagation are shown by red spheres.

unambiguously identify the solvent molecules in the residual electron density. The change from $n$-hexyloxy to 3-phenylpropoxy substituents resulted in a dramatic change in network assembly. Instead of the $2 \mathrm{D} \rightarrow 2 \mathrm{D}$ parallel interpenetrated nets, we observed the assembly of 2-fold interpenetrating $\left(6^{4} \cdot 8^{2}\right) n b o$ nets (Fig. 6a and Table 3). (Readers unfamiliar with the nomenclature and description of 4-connected network notation are referred to the excellent review by Li et al. ${ }^{47}$ ) Crystallization in the trigonal $R \overline{3}$ space group resulted in hexagonal channels running parallel to the $c$-axis, and $\pi$-stacking interactions between the phenyl rings of the $\mathrm{Ph}\left(\mathrm{CH}_{2}\right)_{3} \mathrm{O}$ and $4,2^{\prime}: 6^{\prime}, 4^{\prime \prime}$-tpy units in the adjacent network lock the interpenetrated frameworks tightly together, leaving a large solvent-accessible void space ( $c a .65 \%$ of the total volume). ${ }^{48}$ The radical difference in network on going from $\left[\mathrm{Zn}_{2} \mathrm{Cl}_{4}(\mathbf{6})\right]_{n}$ to $\left[\mathrm{Zn}_{2} \mathrm{Br}_{4}(7)\right]_{n}$ is accomplished with little perturbation of the repeat unit. Fig. $6 \mathrm{~b}$ shows an overlay of the repeat units in each coordination assembly. Note that the terminal $\mathrm{CH}_{2} \mathrm{CH}_{3}$ group in 6 is in close proximity to a $\left\{\mathrm{ZnN}_{2} \mathrm{X}_{2}\right\}$ unit. The introduction of the phenyl ring causes a conformational change such that the $\mathrm{Zn}-\mathrm{N}$ vector changes direction. The positions of symmetry-generated $\mathrm{N}$ atoms which dictate the direction of network propagation are shown as red spheres in Fig. 6b. The structural change on going from 6 to 7 therefore has two effects: (i) it redirects the nitrogen lone pairs that in turn redirect the network propagation, and (ii) it provides an additional $\pi$-stacking motif in the supramolecular assembly which is crucial to locking the interpenetrated nets together.

\section{Ligand-node/metal-node strategy: directing 3D-network assembly}

We now turn to the third strategy for the assembly of extended architectures: using both ligands and metal centres as nodes. We have combined the approaches of using $\mathrm{Co}(\mathrm{NCS})_{2}$ as a metal node with bis( $\left(4,2^{\prime}: 6^{\prime}, 4^{\prime \prime}\right.$-tpy) ligands, and have extended this to the use of bis( $3,2^{\prime}: 6^{\prime}, 3^{\prime \prime}$-tpy) nodes. The expectation was that both $\mathrm{Co}(\mathrm{NCS})_{2}$ and the bis( $\left(4,2^{\prime}: 6^{\prime}, 4^{\prime \prime}\right.$-tpy) and bis( $3,2^{\prime}: 6^{\prime}, 3^{\prime \prime}$-tpy) ligands would function as 4-connecting, topographically planar nodes. However, diversity in 4 -connected nets ${ }^{47}$ makes predicting the outcome of these combinations far from simple, and changes to the alkyloxy substituents (length, straight or branched, presence of an aryl $\pi$-stacking domain) in the ligands are expected to play a dominant role in the assembly process.

Ligands 2 and 3 differ only in the length of the $n$-alkyloxy chains (Scheme 4). The reaction of $\mathrm{Co}(\mathrm{NCS})_{2}$ with 2 yields $\left[\mathrm{Co}(\mathrm{NCS})_{2}(2)_{2}\right]_{n}$ which possesses a $\left(6^{5} \cdot 8\right) \quad c d s$ network (Fig. 7a) in which both $\mathrm{Co}(\mathrm{II})$ and 2 are 4 -connecting nodes. ${ }^{33}\left[\mathrm{Co}(\mathrm{NCS})_{2}(3)_{2}\right]_{n}$ also possesses a $\left(6^{5} \cdot 8\right) c d s$ net. $^{45}$ Table 4 compares the cell parameters of $\left[\mathrm{Co}(\mathrm{NCS})_{2}(2)_{2}\right]_{n}$ and $\left[\mathrm{Co}(\mathrm{NCS})_{2}(3)_{2}\right]_{n}$, and the data confirm that the 3D-network can accommodate either $n$-propyl or $n$-pentyl chains without structural modification. We note that both structures contain 1,2dichlorobenzene solvent molecules.

As discussed earlier (Scheme 3), a change from a bis( $\left(4,2^{\prime}: 6^{\prime}, 4^{\prime \prime}\right.$-tpy) to bis( $\left(3,2^{\prime}: 6^{\prime}, 3^{\prime \prime}\right.$-tpy) 4 -connecting node is accompanied by greater vectorial flexibility. Thus, we anticipated greater variation in network architecture with ligands 8-11 than with 1-7 (Scheme 4). A further degree of conformational freedom that we have so far ignored is rotation about the pyridine-phenylene $\mathrm{C}-\mathrm{C}$ bonds, and indeed this plays a significant role in the $3 \mathrm{D}$-assemblies produced with combinations of $\mathrm{Co}(\mathrm{NCS})_{2}$ and ligands 8, 9, 10 and 11. All products have the same $\left[\mathrm{Co}(\mathrm{NCS})_{2}(\mathbf{L})_{2}\right]_{n}$ stoichiometry (ignoring solvent molecules) and adopt 3D-networks. ${ }^{45,51,52}$ Fig. 8 compares the conformations of the coordinated ligands 8, 9 and 11; $\left[\mathrm{Co}(\mathrm{NCS})_{2}(\mathbf{1 0})_{2}\right]_{n}$ and $\left[\mathrm{Co}(\mathrm{NCS})_{2}(9)_{2}\right]_{n}$ crystallize in the $C 2 / c$ space group with similar cell dimensions and the structures are similar. ${ }^{52}$ Ligands 9, 10 and $\mathbf{1 1}$ adopt conformations in which (i) the $3,2^{\prime}: 6^{\prime}, 3^{\prime \prime}$-tpy domains are close to coplanar and (ii) each $3,2^{\prime}: 6^{\prime}, 3^{\prime \prime}$-tpy adopts conformation II defined in Scheme 3. In contrast, coordinated 8 adopts a conformation in which (i) the $3,2^{\prime}: 6^{\prime}, 3^{\prime \prime}$-tpy domains are approximately orthogonal and (ii) each $3,2^{\prime}: 6^{\prime}, 3^{\prime \prime}$-tpy adopts conformation $\mathbf{I}$ in Scheme 3.

As Fig. 8a shows, the ligand node in $\left[\mathrm{Co}(\mathrm{NCS})_{2}(8)_{2}\right]_{n}$ is topographically close to tetrahedral and this combines with the planar Co nodes to give the binodal $\left\{4^{2} \cdot 8^{4}\right\} l v t$ net depicted in Fig. $7 \mathrm{~b}$. The $n$-octyloxy chains extend into the cavities in the lattice and the terminal $\mathrm{CH}_{2} \mathrm{CH}_{3}$ units of each chain engage in close $\mathrm{CH} \cdots \pi$ contacts with the $3,2^{\prime}: 6^{\prime}, 3^{\prime \prime}$-tpy domains. ${ }^{51}$ In contrast, replacing the $n$-octyloxy by 4 -phenylbutyloxy chains leads to a change in conformation of the ligand (compare Fig. 8b with 8a) and the assembly of a $\left(6^{5} \cdot 8\right) c d s$ network in $\left[\mathrm{Co}(\mathrm{NCS})_{2}(\mathbf{1 1})_{2}\right]_{n}$ (Fig. 7a) in which both the 4-connecting Co

Table 3 Characteristics of 4-connected networks relevant to this article

\begin{tabular}{lll}
\hline Net & Point symbol & Description $^{a}$ \\
\hline$n b o$ & $6^{4} \cdot 8^{2}$ & Adjacent 4-connecting nodes are all perpendicular to one another \\
$c d s$ & $6^{5} \cdot 8$ & Half of the adjacent 4-connecting nodes are perpendicular to one another \\
$l v t$ & $4^{2} \cdot 8^{4}$ & Two of the 4-connecting nodes are coplanar and two are inclined but not perpendicular
\end{tabular}

${ }^{a}$ Descriptions are based on those in ref. 50 . 


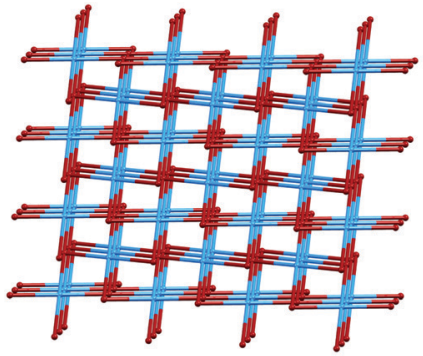

(a)

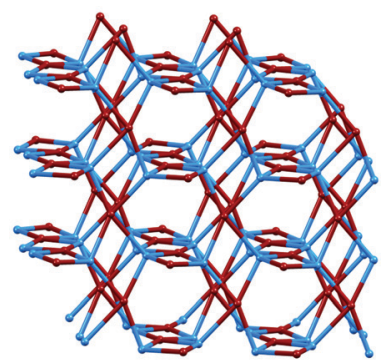

(b)
Fig. 7 (a) The cds net found in $\left[\mathrm{Co}(\mathrm{NCS})_{2}(2)_{2}\right]_{n},\left[\mathrm{Co}(\mathrm{NCS})_{2}(3)_{2}\right]_{n}$, and $\left[\mathrm{Co}(\mathrm{NCS})_{2}(\mathbf{1 1})_{2}\right]_{n}$. (b) The IVt net found in $\left[\mathrm{Co}(\mathrm{NCS})_{2}(\mathbf{8})_{2}\right]_{n}$, with ligand nodes in blue and $\mathrm{Co}$ nodes in maroon. Both diagrams are TOPOS ${ }^{49}$ representations.

Table 4 Unit cell parameters for $c d s$ nets of type $\left[\mathrm{Co}(\mathrm{NCS})_{2}(\mathrm{~L})\right]_{n}$

\begin{tabular}{llllll}
\hline $\mathbf{L}$ & Space group & $a / \AA$ & $b / \AA$ & $c / \AA$ & $\beta /$ deg. \\
\hline $\mathbf{2}$ & $P 2_{1} / c$ & $10.2136(9)$ & $19.3452(17)$ & $16.2214(15)$ & $107.027(3)$ \\
$\mathbf{3}$ & $P 2_{1} / c$ & $10.3756(6)$ & $19.1855(11)$ & $16.2699(9)$ & $106.881(3)$ \\
$\mathbf{1 1}$ & $P 2_{1} / c$ & $13.7465(6)$ & $15.7832(7)$ & $16.2872(8)$ & $112.147(2)$
\end{tabular}
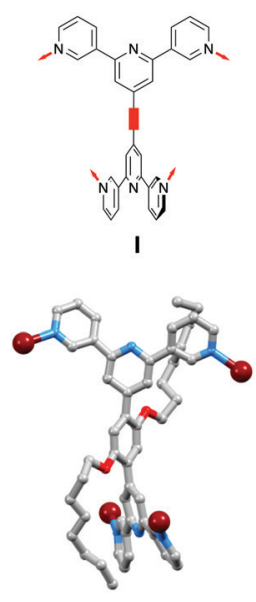

(a)
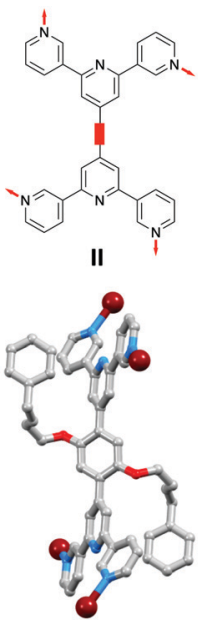

(b)
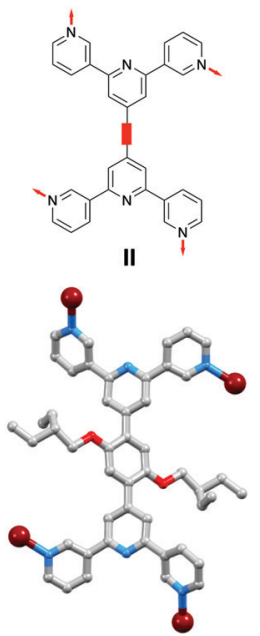

(c)
Fig. 8 Conformational variation of bis $\left(3,2^{\prime}: 6^{\prime}, 3^{\prime \prime}\right.$-tpy) 4-connecting nodes in (a) $\left[\mathrm{Co}(\mathrm{NCS})_{2}(\mathbf{8})_{2}\right]_{n}$ (CSD refcode LOTDIJ), (b) $\left[\mathrm{Co}(\mathrm{NCS})_{2}(\mathbf{1 1})_{2}\right]_{n}$ (refcode KOXJEP), and (c) $\left[\mathrm{Co}(\mathrm{NCS})_{2}(\mathbf{9})\right]_{n}$ (refcode NORVOI). $\mathrm{H}$ atoms are omitted. The conformations I and II are defined in Scheme 3 for each $3,2^{\prime}: 6^{\prime}, 3^{\prime \prime}$-tpy unit.

and ligand nodes are topographically planar. $\left[\mathrm{Co}(\mathrm{NCS})_{2}(2)_{2}\right]_{n}$ and $\left[\mathrm{Co}(\mathrm{NCS})_{2}(3)_{2}\right]_{n}$ (with bis $\left(4,2^{\prime}: 6^{\prime}, 4^{\prime \prime}\right.$-tpy nodes)) and

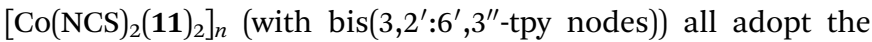
same $c d s$ 3D-architectures (Table 4) despite (i) the vectorial differences of the terpyridine domains (Scheme 3) and (ii) the presence of the terminal phenyl domain in 11. In fact, contrary to expectations, the phenyl ring does not engage in any $\pi$-stacking contacts and, unlike the pendant phenyl in ligand 7 (see Fig. 6), it does not appear to play an important role in directing the network assembly. ${ }^{45}$
This area remains a playground for further exploration, and recently, we have begun to explore the use of branched alkyloxy substituents in bis $\left(4,2^{\prime}: 6^{\prime}, 4^{\prime \prime}\right.$-tpy) and bis $\left(3,2^{\prime}: 6^{\prime}, 3^{\prime \prime}\right.$-tpy) ligands. This has led to the first examples of trinodal self-penetrating $\left(6^{2} \cdot 8^{4}\right)\left(6^{4} \cdot 8^{2}\right)\left(6^{5} \cdot 8\right)^{2}$ nets incorporating terpyridine metalbinding domains. The steric demands of the 2-ethylbutyl and 3-methylbutyl substituents in ligands $\mathbf{9}$ and $\mathbf{1 0}$ (Scheme 3) are similar, and reactions with $\mathrm{Co}(\mathrm{NCS})_{2}$ under conditions of crystal growth by layering yielded $\left[\mathrm{Co}(\mathrm{NCS})_{2}(\mathbf{9})\right]_{n}$ and $\left[\mathrm{Co}(\mathrm{NCS})_{2}(\mathbf{1 0})\right]_{n}$ which were structurally very similar. The 3D-network contains four chemically distinct nodes, all 4-connecting. Since the two ligand nodes are topographically equivalent, the net is trinodal, and Fig. 9 illustrates the self-penetrating network. ${ }^{52}$ The reproducibility of the assembly with ligands $\mathbf{9}$ and $\mathbf{1 0}$ is important, and investigations with related tetratopic ligands are continuing.

\section{A tale (or, rather, tail) of the unexpected}

So far, we have described the use of ditopic $4,2^{\prime}: 6^{\prime}, 4^{\prime \prime}$-tpy and $3,2^{\prime}: 6^{\prime}, 3^{\prime \prime}$-tpy ligands for the assembly of $2 \mathrm{D}$ nets using a metalnode/ligand-linker approach, and of tetratopic bis $\left(4,2^{\prime}: 6^{\prime}, 4^{\prime \prime}-\right.$

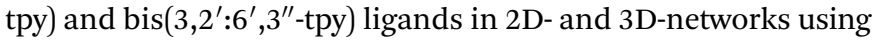
both ligand-node/metal-linker and metal-node/ligand-node strategies. Typically, we expect combinations of $\mathrm{Co}(\mathrm{NCS})_{2}$ and a ditopic ligand to lead to $(4,4)$ nets, although in the case of $4^{\prime}$ $\left(4-\mathrm{HC} \equiv \mathrm{CC}_{6} \mathrm{H}_{4}\right)-4,2^{\prime}: 6^{\prime}, 4^{\prime \prime}$-tpy, a $(6,3)$ net is formed (Table 1$)$. Notice that in Table $1,(4,4)$ nets persist in the $\left[\mathrm{Co}(\mathrm{NSC})_{2}\left\{4^{\prime}-(4-n-\right.\right.$ alkoxyC $\left.\mathrm{C}_{6} \mathrm{H}_{4}\right)-3,2^{\prime}: 6^{\prime}, 3^{\prime \prime}$-tpy $\left.\}_{2}\right]_{n}$ series from $\mathrm{MeO}$ to ${ }^{n} \mathrm{HxO}$. In contrast, the analogous $\left[\mathrm{Co}(\mathrm{NSC})_{2}\left\{4^{\prime}-\left(4-n\right.\right.\right.$-alkoxyC $\left.\mathrm{C}_{6} \mathrm{H}_{4}\right)-4,2^{\prime}: 6^{\prime}, 4^{\prime \prime}$ tpy $\left.\}_{2}\right]_{n}$ series runs only to the ${ }^{n} \mathrm{PrO}$ substituent. The assembly formed when $\mathrm{Co}(\mathrm{NCS})_{2}$ combines with $4^{\prime}-\left(4{ }^{n}{ }^{n} \mathrm{HxOC}_{6} \mathrm{H}_{4}\right)-$ $4,2^{\prime}: 6^{\prime}, 4^{\prime \prime}$-tpy (12, Fig. 10) was both unexpected and unusual. While retaining both the $\left[\mathrm{Co}(\mathrm{NCS})_{2}(\mathbf{L})_{2}\right]_{n}$ stoichiometry of the $(4,4)$ nets, and the Co atoms as 4-connecting nodes, $\left[\mathrm{Co}(\mathrm{NCS})_{2}(\mathbf{1 2})_{2}\right]_{n}$ assembles into a uninodal, 3D, chiral neb net consisting of $6^{6}$ cages (Fig. 10). These units contrast with the $6^{4}$ cages that define a diamond net. Single crystal X-ray diffraction

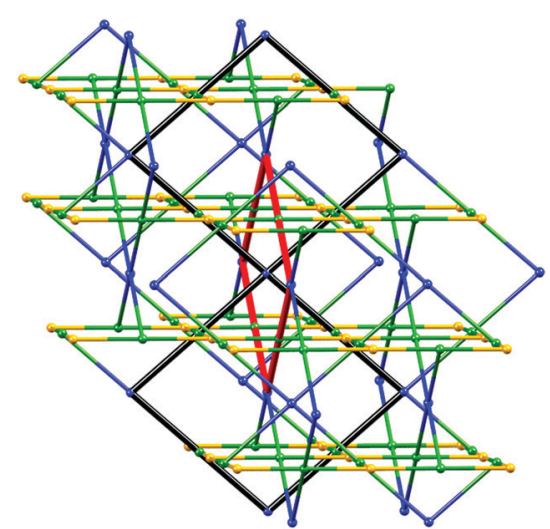

Fig. 9 Part of the trinodal self-penetrating $\left(6^{2} \cdot 8^{4}\right)\left(6^{4} \cdot 8^{2}\right)\left(6^{5} \cdot 8\right)^{2}$ net in $\left[\mathrm{Co}(\mathrm{NCS})_{2}(\mathbf{9})\right]_{n}$ and $\left[\mathrm{Co}(\mathrm{NCS})_{2}(\mathbf{1 0})\right]_{n}$ (CSD refcodes NORVAU and NORVOI) with the interlocking of the shortest circuits shown in red and black. Chemically distinct Co nodes are shown in blue and yellow, and the ligand nodes in green. 

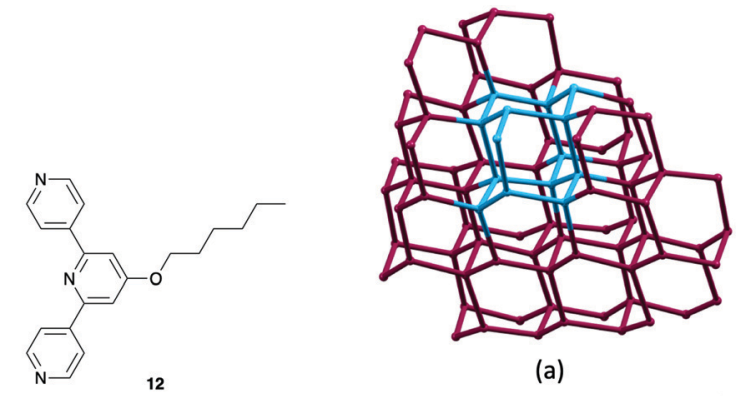

(a)

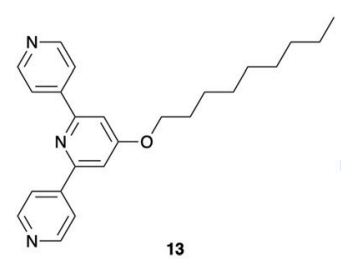

13

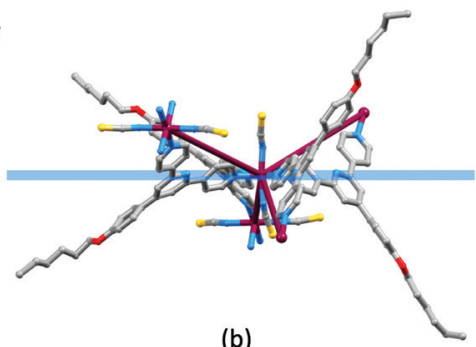

(b)

Fig. 10 Structures of ditopic ligands 12 and 13. (a) Part of the neb net in $\left[\mathrm{Co}(\mathrm{NCS})_{2}(12)_{2}\right]_{n}$ showing the Co nodes. One $6^{6}$ unit of the neb topology is highlighted in blue. (CSD refcode EMEJIR, TOPOS ${ }^{49}$ representation.) (b) The octahedral coordination geometry of the trans- $\left\{\mathrm{Co}(\mathrm{NCS})_{2} \mathrm{~N}_{4}\right\}$ unit places the pyridine $\mathrm{N}$-donors in a plane (in blue), but the Co node in the network is topographically tetrahedral (maroon connections).

data delineated both enantiomorphic lattices of the neb nets which crystallized in the tetragonal space groups $P 4_{1} 2_{1} 2$ and $P 4_{3} 2_{1} 2$, respectively. It is especially striking that the chiral architecture is produced from achiral nodes and linkers. When we consider an octahedral trans $-\left\{\mathrm{Co}(\mathrm{NCS})_{2} \mathrm{~N}_{4}\right\}$ unit, we are undoubtedly programmed to think of the $\mathrm{CoN}_{4}$ unit as planar. In the neb net, the Co nodes are topographically tetrahedral and Fig. 10b illustrates the relationship between the planar $\left\{\mathrm{CoN}_{4}\right\}$ unit and the 4-connecting node in the net. Fig. 10b shows that the $n$-hexyl chains are in extended conformations and (comparing Fig. 10b with 10a) are threaded through the lattice. A comparable situation arises in $\left[\mathrm{Co}(\mathrm{NCS})_{2}(\mathbf{1 3})_{2}\right]_{n}$ which also adopts a chiral neb net. ${ }^{53}$ We propose that, as in the $2 \mathrm{D} \rightarrow 2 \mathrm{D}$ parallel interpenetrated sheets described earlier, ${ }^{43-45}$ the presence of the long $n$-alkyloxy chains extending through voids in the lattice exhibits a stabilizing influence on the assembly.

\section{Conclusions}

Over the last decade, ditopic $4,2^{\prime}: 6^{\prime}, 4^{\prime \prime}$-tpy ligands have become popular linkers in coordination polymers and 2D-networks, and functionalization in the $4^{\prime}$-position has the potential to access a vast toolbox of new ligands. Assemblies may be redirected by use of $3,2^{\prime}: 6^{\prime}, 3^{\prime \prime}$-tpy metal-binding domains which are conformationally more adaptable than $4,2^{\prime}: 6^{\prime}, 4^{\prime \prime}$-tpy. Tetratopic bis $\left(4,2^{\prime}: 6^{\prime}, 4^{\prime \prime}\right.$-tpy) and bis( $3,2^{\prime}: 6^{\prime}, 3^{\prime \prime}$-tpy) ligands function as 4 -connecting nodes and the conformational flexibility of these ligand backbones makes these attractive building blocks in 3D-architectures, and we have demonstrated the assembly of a range of 3D-networks. Nonetheless, we are far from understanding the assembly algorithms and further systematic investigations are much needed. This is true, not only in terpyridine-isomer coordination chemistry, but in areas of coordination polymer and network assembly in general.

And what of the future? Although most of the solid state crystalline materials have been obtained by liquid-liquid or liquid-vapour diffusion methods, we are also routinely using PXRD to show that bulk materials obtained under 'normal' synthetic conditions possess the same or similar structures. The future development of these systems is likely to involve studies of materials growth under conditions far from equilibrium such as microwave, hydrothermal and ultrasonic reactions. Preliminary studies have shown that reactions under microwave conditions generally yield the same products.

\section{Conflicts of interest}

There are no conflicts to declare.

\section{Acknowledgements}

We acknowledge the continued support of the Swiss National Science Foundation (current grant numbers 200020_182000 and 200020_182559) and the University of Basel. None of the beautiful architectures that we have described from our own work would have been possible without the dedicated and enthusiastic work of members of our research group and of our X-ray crystallographic colleagues whose names appear in the cited literature.

\section{References}

1 E. C. Constable, Adv. Inorg. Chem. Radiochem., 1986, 30, 69.

2 E. C. Constable, Chem. Soc. Rev., 2007, 36, 246.

3 E. C. Constable and C. E. Housecroft, Coord. Chem. Rev., 2017, $350,84$.

4 E. C. Constable, Adv. Inorg. Chem., 2018, 71, 79.

5 E. C. Constable, Coord. Chem. Rev., 2008, 252, 842.

6 J. E. Beves, E. C. Constable, S. Decurtins, E. L. Dunphy, C. E. Housecroft, T. D. Keene, M. Neuburger and S. Schaffner, CrystEngComm, 2008, 10, 986.

7 J. Wang and G. S. Hanan, Synlett, 2005, 1251.

8 F. Kröhnke, Synthesis, 1976, 1.

9 D. Rocco, C. E. Housecroft and E. C. Constable, Molecules, 2019, 24, 1799.

10 C. R. Groom, I. J. Bruno, M. P. Lightfoot and S. C. Ward, Acta Crystallogr., Sect. B: Struct. Sci., Cryst. Eng. Mater., 2016, B72, 171.

11 M. Yoshizawa, T. Kusukawa, M. Fujita, S. Sakamoto and K. Yamaguchi, J. Am. Chem. Soc., 2001, 123, 10454.

12 Y. Kubota, K. Biradha, M. Fujita, S. Sakamoto and K. Yamaguchi, Bull. Chem. Soc. Jpn., 2002, 75, 559.

13 T. Wang, L. Qin, C. Zhang and H. Zheng, RSC Adv., 2015, 5, 64514.

14 F. Thebault, S. A. Barnett, A. J. Blake, C. Wilson, N. R. Champness and M. Schröder, Inorg. Chem., 2006, 45, 6179.

15 C.-L. Zhang, H. Xu, X.-W. Song, Y. Meng and J.-J. Chen, Inorg. Chem. Commun., 2017, 84, 229.

16 J. P. Barrio, J.-N. Rebilly, B. Carter, D. Bradshaw, J. Bacsa, A. Y. Ganin, H. Park, A. Trewin, R. Vaidhyanathan, A. I. Cooper, J. E. Warren and M. J. Rosseinsky, Chem. - Eur. J., 2008, 14, 4521.

17 C.-L. Zhang, H.-Y. Wang and H.-G. Zheng, Chin. J. Inorg. Chem., 2016, 32, 859.

18 J.-Y. Li, Y.-C. Chen, Z.-M. Zhang, W. Liu, Z.-P. Ni and M.-L. Tong, Chem. - Eur. J., 2015, 21, 1645.

19 M. Maekawa, T. Hayashi, K. Sugimoto, T. Okubo and T. KurodaSowa, Inorg. Chim. Acta, 2019, 497, 119088. 
20 See for example: U. P. Singh, S. Narang, P. Pachfule and R. Banerjee, CrystEngComm, 2014, 16, 5012; S. Khatua, S. Goswami, S. Biswas, K. Tomar, H. S. Jena and S. Konar, Chem. Mater., 2015, 27, 5349; P. Yang, M.-S. Wang, J.-J. Shen, M.-X. Li, Z.-X. Wang, M. Shao and X. He, Dalton Trans., 2014, 43, 1460; F. Yuan, X. Wang, H.-M. Hu, S.-S. Shen, R. An and G.-L. Xue, Inorg. Chem. Commun., 2014, 48, 26; X.-Z. Li, X.-P. Zhou, D. Li and Y.-G. Yin, CrystEngComm, 2011, 13, 6759; M. Zhao, J. Tan, J. Su, J. Zhang, S. Zhang, J. Wu and Y. Tian, Dyes Pigm., 2016, 130, 216; G. Zhang, J. Tan, T. Phoenix, D. R. Manke, J. A. Golen and A. L. Rheingold, RSC Adv., 2016, 6, 9270; G. Zhang, Y.-X. Jia, W. Chen, W.-F. Lo, N. Braithwaite, J. A. Golen and A. L. Rheingold, RSC Adv., 2015, 5, 15870; L. Li, E. Liu, J. Cheng and G. Zhang, Dalton Trans., 2018, 47, 9579; L. Li, Y. Z. Zhang, C. Yang, E. Liu, J. A. Golen and G. Zhang, Polyhedron, 2016, 105, 115; X.-Z. Li, M. Li, J.-Z. Hou, X.-C. Huang and D. Li, Angew. Chem., Int. Ed., 2008, 47, 6371; S. Zhu, X.-J. Dai, X.-G. Wang, Y.-Y. Cao, X.-J. Zhao and E.-C. Yang, Z. Anorg. Allg. Chem., 2019, 645, 516; X. L. Gao, Y. Gong, P. Zhang, Y. X. Yang, J. P. Meng, M. M. Zhang, J. L. Yina and J. H. Lin, CrystEngComm, 2014, 16, 8492; L. Zhang, J.-D. Zheng, Y.-T. Chen, S.-R. Zheng, J. Fan and W.-G. Zhang, CrystEngComm, 2015, 17, 5538; D. Toledo, A. Vega, N. Pizarro, R. Baggio, O. Pena, T. Roisnel, J.-Y. Pivan and Y. Moreno, J. Solid State Chem., 2017, 253, 78; J. Sun, J. Zhang, X. Tian, M. Zhao, T. Song, J. Yu, Y. Cui, G. Qian, H. Zhong, L. Luo, Y. Zhang, C. Wang, S. Li, J. Yang, H. Zhou, J. Wu and T. Tian, J. Mater. Chem. B, 2017, 5, 5458; L. Xiao, L. Zhu, Q. Zeng, Q. Liu, J. Zhang, S. Li, H. Zhou, S. Zhang, J. Wu and Y. Tian, J. Organomet. Chem., 2015, 789-790, 22; L. Zhang, C.-J. Li, J.-E. He, Y.-Y. Chen, S.-R. Zheng, J. Fan and W.-G. Zhang, J. Solid State Chem., 2016, 233, 444; L. Lu, J. Wang, W.-P. Wu, A. Ma, J.-Q. Liu, R. Yadav and A. Kumar, J. Lumin., 2017, 186, 40.

21 J. Yoshida, S. Nishikiori and H. Yuge, J. Coord. Chem., 2013, 66, 2191.

22 E. C. Constable and A. M. W. C. Thompson, J. Chem. Soc., Chem. Commun., 1992, 617.

23 D. Rocco, A. Prescimone, E. C. Constable and C. E. Housecroft, Molecules, 2020, 25, 3162.

24 D. Rocco, G. Manfroni, A. Prescimone, Y. M. Klein, D. J. Gawryluk, E. C. Constable and C. E. Housecroft, Polymers, 2020, 12, 318.

25 D. Rocco, A. Prescimone, E. C. Constable and C. E. Housecroft, Molecules, 2020, 25, 1663.

26 M. Barquin, J. Cancela, M. J. González Garmendia, J. Quintanilla and U. Amador, Polyhedron, 1998, 17, 2372.

27 C. E. Housecroft, Dalton Trans., 2014, 43, 6594.

28 C. E. Housecroft, CrystEngComm, 2015, 17, 7461.

29 E. C. Constable and C. E. Housecroft, J. Inorg. Organomet. Polym. Mater., 2018, 28, 414.
30 C. E. Housecroft and E. C. Constable, Chimia, 2019, 73, 462.

31 Y. M. Klein, E. C. Constable, C. E. Housecroft, J. A. Zampese and A. Crochet, CrystEngComm, 2014, 16, 9915.

32 E. C. Constable, G. Zhang, C. E. Housecroft and J. A. Zampese, CrystEngComm, 2011, 13, 6864.

33 Y. M. Klein, A. Prescimone, E. C. Constable and C. E. Housecroft, Materials, 2017, 10, 728.

34 D. Rocco, A. Prescimone, Y. M. Klein, D. J. Gawryluk, E. C. Constable and C. E. Housecroft, Polymers, 2019, 11, 1224.

35 J. Heine, J. Sauf der Gunne and S. Dehnen, J. Am. Chem. Soc., 2011, 133, 10018.

36 E. C. Constable, C. E. Housecroft, P. Kopecky, M. Neuburger, J. A. Zampese and G. Zhang, CrystEngComm, 2012, 14, 446.

37 Y. M. Klein, A. Prescimone, E. C. Constable and C. E. Housecroft, Polyhedron, 2016, 103A, 58.

38 E. C. Constable, G. Zhang, C. E. Housecroft, M. Neuburger and J. A. Zampese, CrystEng.Comm, 2009, 11, 2279.

39 E. C. Constable, C. E. Housecroft, M. Neuburger, S. Vujovic, J. A. Zampese and G. Zhang, CrystEngComm, 2012, 14, 3554.

40 A. K. Mondal, S. Khatua, K. Tomar and S. Konar, Eur. J. Inorg. Chem., $2016,3545$.

41 A. Bondi, J. Phys. Chem., 1964, 68, 441.

42 R. S. Rowland and R. Taylor, J. Phys. Chem., 1996, 100, 7384.

43 S. Vujovic, E. C. Constable, C. E. Housecroft, C. D. Morris, M. Neuburger and A. Prescimone, Polyhedron, 2015, 92, 77.

44 E. C. Constable, C. E. Housecroft, S. Vujovic and J. A. Zampese, CrystEngComm, 2014, 16, 3494, correction, CrystEngComm, 2017, 19, 2271.

45 Y. M. Klein, A. Prescimone, M. Karpacheva, E. C. Constable and C. E. Housecroft, Polymers, 2018, 10, 1369.

46 A. L. Spek, Acta Crystallogr., Sect. C: Struct. Chem., 2015, 71, 9.

47 D.-S. Li, Y.-P. Wu, J. Zhao, J. Zhang and J. K. Lu, Coord. Chem. Rev., 2014, 261, 1.

48 Y. M. Klein, A. Prescimone, M. Neuburger, E. C. Constable and C. E. Housecroft, CrystEngComm, 2017, 19, 2894.

49 V. A. Blatov and A. P. Shevchenko, TOPOS Professional v. 4.0, Samara State University, Russia, 2014.

50 S. R. Batten, S. M. Neville and D. R. Turner, Coordaintion Polymers: Design, Analysis and Application, RSC Publishing, Cambridge, 2009, ch. 2 .

51 Y. M. Klein, E. C. Constable, C. E. Housecroft and A. Prescimone, CrystEngComm, 2015, 17, 2070.

52 G. Manfroni, A. Prescimone, S. R. Batten, Y. M. Klein, D. J. Gawryluk, E. C. Constable and C. E. Housecroft, Crystals, 2019, 9, 529.

53 Y. M. Klein, A. Prescimone, M. B. Pitak, S. J. Coles, E. C. Constable and C. E. Housecroft, CrystEngComm, 2016, 18, 4704. 